\title{
Mass spectrometric studies of competitive binding of $\mathrm{C}_{60}$ and $\mathrm{C}_{70}$ to meso- substituted porphyrins
}

\author{
Sunghan Jung and Seung Koo Shin* \\ FT-ICR Laboratory, Department of Chemistry, Pohang University of Science and Technology, Pohang 790-784, Korea
}

Received May 19, 2011; Revised June 7, 2011; Accepted June 8, 2011

First published on the web June 15, 2011; DOI: 10.5478/MSL.2011.2.2.049

\begin{abstract}
Competitive binding of $\mathrm{C}_{60}$ and $\mathrm{C}_{70}$ to meso-substituted porphyrins was studied by mass spectrometry (MS). Electrospray ionization MS was employed to acquire the mass spectra of $1: 1$ porphyrin-fullerene complexes formed in a mixture of mesosubstituted porphyrin and fullerite to determine the ratio of complexes between $\mathrm{C}_{60}$ and $\mathrm{C}_{70}$. Matrix-free laser desorption ionization MS was used to obtain the mass spectra of fullerite to measure the mole fraction of $\mathrm{C}_{60}$ and $\mathrm{C}_{70}$. The binding constant ratio $\left(K_{70} / K_{60}\right)$ was determined from the mass spectral data. The difference in standard Gibbs free energy change, $\Delta\left(\Delta G^{0}\right)_{70-60}$, for the competitive binding of $\mathrm{C}_{60}$ and $\mathrm{C}_{70}$ was calculated from $K_{70} / K_{60}$. Of the five porphyrins, tetraphenyl, tetra(4-pyridyl), tetra(4-carboxyphenyl), tetra(3,5-di-tert-butylphenyl), and tetra(pentafluorophenyl) porphyrins, the first three non-bulky porphyrins yield negative values of $\Delta\left(\Delta G^{0}\right)_{70-60}$, whereas the other two bulky porphyrins result in positive values of $\Delta\left(\Delta G^{0}\right)_{70-60}$. This result indicates that $\mathrm{C}_{70}$ binding to porphyrin is thermodynamically favored over $\mathrm{C}_{60}$ binding in non-bulky porphyrins, but disfavored in bulky ones. It also suggests that the binding mode of $\mathrm{C}_{70}$ is different between non-bulky and bulky porphyrins, which is in line with previous experimental findings of the "side-on" binding to non-bulky porphyrins and the $\mathrm{C}_{60}$-like "end-on" binding to bulky porphyrins.
\end{abstract}

Key words: Protonated porphyrin, Fullerene, Porphyrin-fullerene complex, Binding constant

Noncovalent binding of curved fullerene to flat porphyrin has attracted much interest because of their unique structures ${ }^{1}$ and potential applications to photovoltaic solar cells. ${ }^{2}$ Selective binding of fullerenes to porphyrin receptors has been used to separate fullerenes using chromatography. ${ }^{3,4}$ Although several binding constant measurements have been reported to date, most of them deal with fullerene binding to bisporphyrins, ${ }^{5-9}$ because bisporphyrin-fullerene complexes show characteristic spectral changes, such as charge-transfer bands in the near-infrared region $^{5,6}$ and redshift in the Soret band ${ }^{5,7-9}$ However, the fullerene binding to monomeric porphyrins has rarely been studied because of the absence of characteristic spectral changes. ${ }^{8,10,11}$ In such a case, mass spectrometry (MS) is a powerful alternative tool to measure the binding constant of host-guest complexes in solution. ${ }^{12}$

Most recently, we utilized collision-induced dissociation MS to study the relative stabilities of protonated porphyrinfullerene complexes in the gas phase. ${ }^{13}$ In the present study, we employed MS to examine the competitive binding of $\mathrm{C}_{60}$ and $\mathrm{C}_{70}$ to five different meso-substituted porphyrins; tetraphenyl porphyrin (1), tetra(4-pyridyl) porphyrin (2), tetra(4 carboxyphenyl) porphyrin (3), tetra(3,5-di-tert-butylphenyl) porphyrin (4), and tetra(pentafluorophenyl) porphyrin (5). Fullerite (a mixture of $\mathrm{C}_{60}$ and $\mathrm{C}_{70}$ ) was used as guest molecules.

Electrospray ionization (ESI) MS was used to take the

*Reprint requests to Dr. Seung Koo Shin

E-mail:skshin@postech.ac.kr

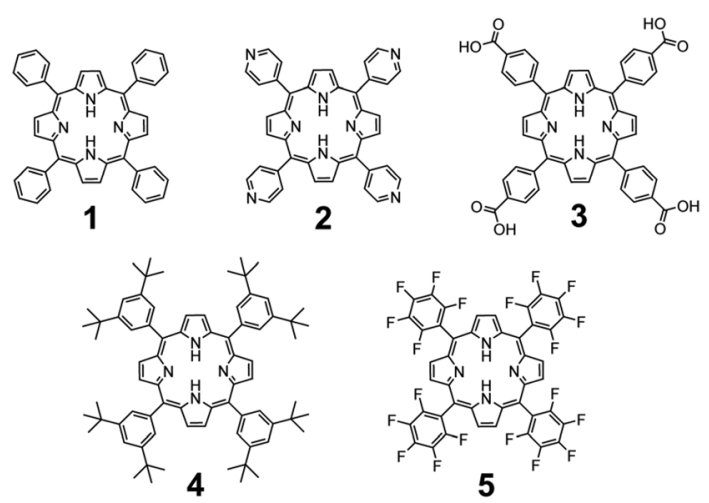

mass spectra of $1: 1$ porphyrin-fullerene complexes formed in a mixture of porphyrin and fullerite in order to determine the relative abundances of $1: 1$ porphyrin- $\mathrm{C}_{60}$ and porphyrin$\mathrm{C}_{70}$ complexes. Matrix-free laser desorption ionization (LDI) MS was used to acquire the mass spectra of fullerite to determine the mole fraction of $\mathrm{C}_{60}$ and $\mathrm{C}_{70}$. The binding constant ratio $\left(K_{70} / K_{60}\right)$ was calculated from the complex and $\mathrm{C}_{60} / \mathrm{C}_{70}$ ratios, and then converted to the Gibbs free energy change. Thermodynamic data for the competitive binding of $\mathrm{C}_{60}$ and $\mathrm{C}_{70}$ to porphyrins show the effects of meso-substituents on the binding mode.

\section{Experimental}

Porphyrins 1 (97\%), 2 (97\%), 3 (75\%), and 5, as well as 
fullerite and pure $\mathrm{C}_{60}(99.5 \%)$ were purchased from SigmaAldrich (St. Louis, MO). Pure $\mathrm{C}_{70}(99.5 \%)$ was obtained from Materials Technologies Research (Cleveland, $\mathrm{OH}$ ). Porphyrin 4 was provided by Dr. P. D. W. Boyd (University of Auckland, New Zealand). HPLC-grade methanol and dichloromethane were purchased from J. T. Baker (Phillipsburg, NJ).

Both porphyrin and fullerite were mixed in a $3: 1(\mathrm{v} / \mathrm{v})$ dichloromethane/methanol solution by 10 -min sonication. The solute concentration was $50 \mu \mathrm{M}$ for porphyrin and $168 \mu \mathrm{M}$ for fullerite. For ESI, $0.5 \%$ formic acid was added to the sample solution. The ESI mass spectra of a porphyrin-fullerene mixture were taken with a triple quadrupole-time-of-flight (TOF) mass spectrometer (QSTAR Pulsar-i, AB Sciex, Foster City, CA), as previously described in detail. ${ }^{13}$ The LDI mass spectra of fullerite as well as pure $\mathrm{C}_{60}$ and $\mathrm{C}_{70}$ were obtained using a TOF mass spectrometer (4700 Proteomics Analyzer, AB Sciex) equipped with a $\mathrm{Nd}$ : YAG laser $(355 \mathrm{~nm})$. The known molar ratio of $\left[\mathrm{C}_{60}\right] /\left[\mathrm{C}_{70}\right]=0.2,0.33,1.0,3.0$, and 5.0 was prepared by dissolving $0.017 / 0.101,0.029 / 0.101,0.072 / 0.084,0.086 /$ 0.034 , and $0.086 / 0.020 \mathrm{mg}$ of pure $\mathrm{C}_{60} / \mathrm{C}_{70}$ in $1 \mathrm{~mL}$ of toluene. A fullerite solution was prepared by dissolving $0.075 \mathrm{mg}$ of fullerite in $1 \mathrm{~mL}$ of toluene.

\section{Results and Discussion}

The mass spectra of fullerite are shown in Figure 1(a). The molar ratio of $\left[\mathrm{C}_{60}\right] /\left[\mathrm{C}_{70}\right]$ in fullerite was determined from a plot of the intensity ratio of $\mathrm{I}\left(\mathrm{C}_{60}{ }^{+}\right) / \mathrm{I}\left(\mathrm{C}_{70}{ }^{+}\right)$as a function of

(a)

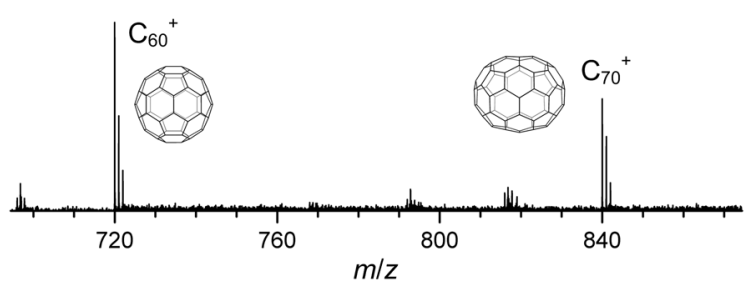

(b)

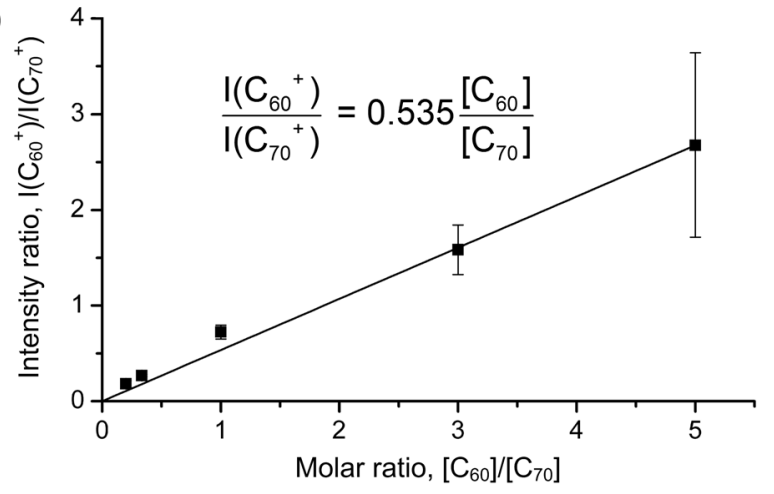

Figure 1. (a) LDI mass spectra of fullerite (a mixture of $\mathrm{C}_{60}$ and $\mathrm{C}_{70}$ ). (b) Plot of the measured intensity ratio of $\mathrm{I}\left(\mathrm{C}_{60}{ }^{+}\right) / \mathrm{I}\left(\mathrm{C}_{70}{ }^{+}\right)$as a function of the premixed molar ratio of pure $\mathrm{C}_{60}$ and $\mathrm{C}_{70},\left[\mathrm{C}_{60}\right] /\left[\mathrm{C}_{70}\right]$. The slope is the response factor for LDI. Error bars are from standard deviations of five measurements. the known molar ratio of pure $\left[\mathrm{C}_{60}\right] /\left[\mathrm{C}_{70}\right]$ (Figure $1(\mathrm{~b})$ ), as previously described by Cristadoro et al ${ }^{14}$ Since ionization energies of $\mathrm{C}_{60}\left(7.6 \mathrm{eV}^{15}\right)$ and $\mathrm{C}_{70}\left(7.47 \mathrm{eV}^{16}\right)$ are different, their response factors for LDI are not identical. A least-squares fit to the data yields the slope of 0.535 as the response factor for $\mathrm{C}_{60}$ relative to $\mathrm{C}_{70}$. Thus, the measured intensity ratio of $\mathrm{I}_{\left(\mathrm{C}_{60}{ }^{+}\right) /}$/ $\mathrm{I}\left(\mathrm{C}_{70}{ }^{+}\right)=1.54 \pm 0.01$ divided by 0.535 results in the molar ratio of $\left[\mathrm{C}_{60}\right]_{0} /\left[\mathrm{C}_{70}\right]_{0}=2.88 \pm 0.03$, suggesting the mole fraction of 0.742 for $\mathrm{C}_{60}$ and 0.258 for $\mathrm{C}_{70}$ in fullerite, which corresponds to $125 \mu \mathrm{M}$ of $\mathrm{C}_{60}$ and $43 \mu \mathrm{M}$ of $\mathrm{C}_{70}$ in $168 \mu \mathrm{M}$ of fullerite.

The ESI mass spectra of protonated porphyrin-fullerene complexes are displayed in Figure 2(a)-(e). Porphyrin (P) forms $1: 1[\mathrm{P}+\mathrm{H}]^{+} \cdot \mathrm{C}_{m}(m=60,70)$ complexes. Their intensity ratio, $\mathrm{I}\left([\mathrm{P}+\mathrm{H}]^{+} \cdot \mathrm{C}_{60}\right) / \mathrm{I}\left([\mathrm{P}+\mathrm{H}]^{+} \cdot \mathrm{C}_{70}\right)$, significantly varies with meso-substituent, indicating that meso-substituents affect the binding equilibrium between porphyrin and fullerene. In the ESI solution containing $0.5 \%$ formic acid, all of the porphyrins

(a)

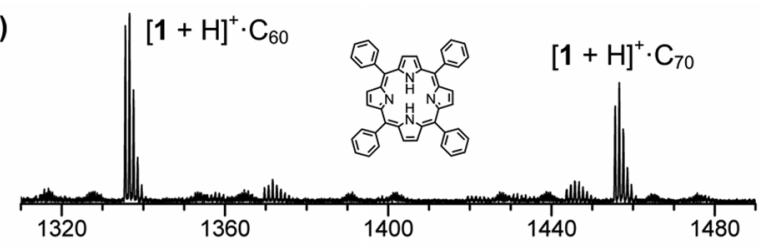

(b)

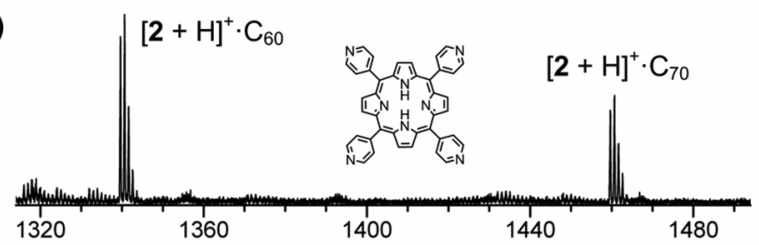

(c)

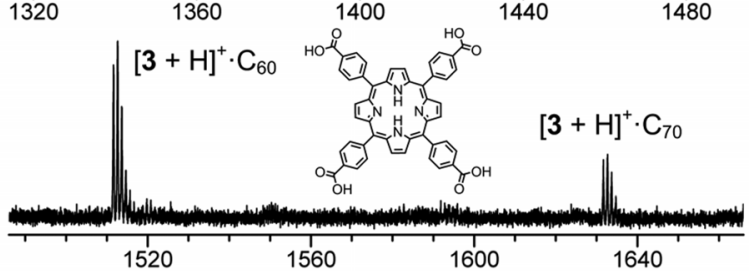

(d)

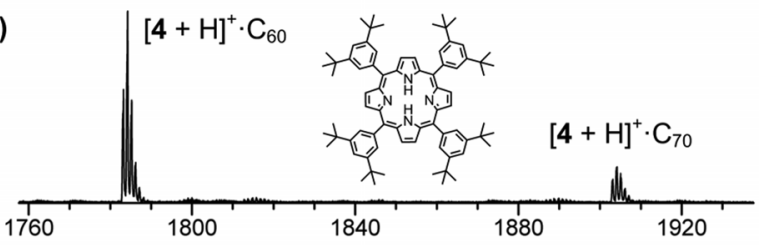

(e)

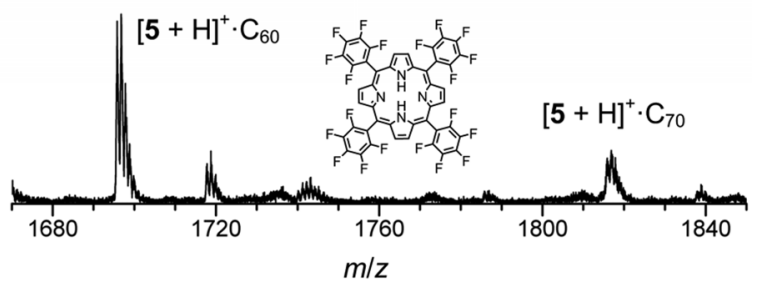

Figure 2. ESI mass spectra of 1:1 porphyrin-fullerene complexes in a porphyrin-fullerite mixture: (a) tetraphenyl porphyrin (1); (b) tetra(4-pyridyl) porphyrin (2); (c) tetra(4-carboxyphenyl) porphyrin (3); (d) tetra(3,5-di-tert-butylphenyl) porphyrin (4); (e) tetra(pentafluorophenyl) porphyrin (5). 
are considered to be protonated, as the proton affinity of porphyrin is $233-263 \mathrm{kcal} \mathrm{mol}^{-1}$. $^{13}$ Thus, the protonated porphyrin $[\mathrm{P}+\mathrm{H}]^{+}$competitively forms $1: 1[\mathrm{P}+\mathrm{H}]^{+} \cdot \mathrm{C}_{m}$ $(m=60,70)$ complexes, as expressed in eq 1 .

$$
\begin{aligned}
& {[\mathrm{P}+\mathrm{H}]^{+} \cdot \mathrm{C}_{60}+\mathrm{C}_{70} \rightleftarrows[\mathrm{P}+\mathrm{H}]+\cdot \mathrm{C}_{70}+\mathrm{C}_{60},} \\
& \frac{\left[[\mathrm{P}+\mathrm{H}]^{+} \cdot \mathrm{C}_{70}\right]}{\left[[\mathrm{P}+\mathrm{H}]^{+} \cdot \mathrm{C}_{60}\right]} \cdot \frac{\left[\mathrm{C}_{60}\right]}{\left[\mathrm{C}_{70}\right]}=\frac{K_{70}}{K_{60}} \approx \frac{I\left([\mathrm{P}+\mathrm{H}]^{+} \cdot \mathrm{C}_{70}\right)}{I\left([\mathrm{P}+\mathrm{H}]^{+} \cdot \mathrm{C}_{60}\right)} \cdot \frac{\left[\mathrm{C}_{60}\right]_{0}}{\left[\mathrm{C}_{70}\right]_{0}},
\end{aligned}
$$

where $\left[[\mathrm{P}+\mathrm{H}]^{+} \cdot \mathrm{C}_{m}\right]$ and $\left[\mathrm{C}_{m}\right]$ are the equilibrium concentrations of complex and uncomplexed fullerene present in solution, respectively, and $K_{m}$ is the $1: 1$ binding constant. By assuming identical ESI response factors for the two complex ions, we can replace the concentration ratio $\left[[\mathrm{P}+\mathrm{H}]^{+} \cdot \mathrm{C}_{70}\right] /\left[[\mathrm{P}+\mathrm{H}]^{+} \cdot \mathrm{C}_{60}\right]$ with the intensity ratio $\mathrm{I}\left([\mathrm{P}+\mathrm{H}]^{+} \cdot \mathrm{C}_{70}\right) /\left(\left[\left([\mathrm{P}+\mathrm{H}]^{+} \cdot \mathrm{C}_{60}\right)\right.\right.$. Moreover, the ratio of $\left[\mathrm{C}_{60}\right] /\left[\mathrm{C}_{70}\right]$ is set to be equal to the initial concentration ratio of $\left[\mathrm{C}_{60}\right]_{0} /\left[\mathrm{C}_{70}\right]_{0}=2.88 \pm 0.03$ in fullerite, because the concentrations of complexed fullerenes are negligible as compared to the initial concentrations of $\mathrm{C}_{60}$ $(125 \mu \mathrm{M})$ and $\mathrm{C}_{70}(43 \mu \mathrm{M})$. The complexed fullerene concentrations $\left(0.5-3.3 \mu \mathrm{M}\right.$ for $\mathrm{C}_{60}$ and $0.3-0.9 \mu \mathrm{M}$ for $\left.\mathrm{C}_{70}\right)$ are estimated by multiplying the initial concentration of porphyrin and the intensity ratio of the complexed porphyrin ions to the sum of all porphyrin-containing ions.

Values of $\mathrm{I}\left([\mathrm{P}+\mathrm{H}]^{+} \cdot \mathrm{C}_{70}\right) / \mathrm{I}\left([\mathrm{P}+\mathrm{H}]^{+} \cdot \mathrm{C}_{60}\right)$ for porphyrins 1-5 are obtained from the ESI mass spectra (Figure 2(a)-(e)). Calculated $K_{70} / K_{60}$ values are listed in Table $1 . K_{70} / K_{60}$ values are greater than one; $1.58 \pm 0.02,1.62 \pm 0.02$, and $1.26 \pm 0.03$ for $\mathbf{1}, \mathbf{2}$, and $\mathbf{3}$, respectively, indicating that equilibrium is shifted toward the binding of $\mathrm{C}_{70}$ for the three non-bulky porphyrins. On the other hand, $K_{70} / K_{60}$ values are less than one; $0.54 \pm 0.01$ and $0.81 \pm 0.01$ for $\mathbf{4}$ and $\mathbf{5}$, respectively, suggesting that the binding of $\mathrm{C}_{60}$ is favored over the $\mathrm{C}_{70}$ binding for the two bulky porphyrins.

In comparison, fluorescence studies yielded $K_{70} / K_{60}=8.7$

Table 1. The ratio of binding constants, $K_{70} / K_{60}$, the change in Gibbs free energy, $\Delta\left(\Delta G^{\circ}\right)_{70-60}$, and the difference in binding energy, $\Delta(\Delta E)_{70-60}$, for competitive binding of $\mathrm{C}_{60}$ and $\mathrm{C}_{70}$ to protonated porphyrins.

\begin{tabular}{ccccc}
\hline \hline \multirow{2}{*}{ porphyrin } & \multirow{2}{*}{$K_{70} / K_{60}{ }^{a}$} & \multirow{2}{*}{$\begin{array}{c}\Delta\left(\Delta G^{\mathrm{o}}\right)_{70-60}{ }^{b} \\
\left(\mathrm{kcal} \mathrm{mol}^{-1}\right)\end{array}$} & \multicolumn{2}{c}{$\Delta(\Delta E)_{70-60}{ }^{c}\left(\mathrm{kcal} \mathrm{mol}^{-1}\right)$} \\
\hline$[\mathbf{1}+\mathrm{H}]^{+}$ & $1.58 \pm 0.02$ & $-0.27 \pm 0.01$ & -2.1 & -0.4 \\
{$[\mathbf{2}+\mathrm{H}]^{+}$} & $1.62 \pm 0.02$ & $-0.29 \pm 0.01$ & -2.3 & -0.4 \\
{$[\mathbf{3}+\mathrm{H}]^{+}$} & $1.26 \pm 0.03$ & $-0.14 \pm 0.02$ & -2.6 & -0.8 \\
{$[\mathbf{4}+\mathrm{H}]^{+}$} & $0.54 \pm 0.01$ & $0.36 \pm 0.01$ & 2.2 & -0.5 \\
{$[\mathbf{5}+\mathrm{H}]^{+}$} & $0.81 \pm 0.01$ & $0.13 \pm 0.01$ & -0.9 & -0.3 \\
\hline
\end{tabular}

${ }^{a}$ Errors are from the standard deviation of the signal-to-noise ratio and curve fitting.

${ }^{b} \Delta\left(\Delta G^{0}\right)_{70-60}=-R T \ln \left(K_{70} / K_{60}\right)$

${ }^{c} \Delta(\Delta E)_{70-60}$ is the difference in binding energy. ${ }^{13}$ in toluene for tetra(octadecyloxyphenyl) porphyrin, ${ }^{11}$ and $\mathrm{UV} /$ visible and fluorescence studies resulted in $K_{70} / K_{60}=1.9$ and 9.0 in toluene for calix[4]arene-linked bisporphyrins with pentafluorophenyl and 3,5-di-tert-butylphenyl meso-substituents, respectively. ${ }^{6}$ Although other studies show that porphyrins favor the binding of $\mathrm{C}_{70}$ over $\mathrm{C}_{60}$ in toluene, we find that nonbulky porphyrins prefer the binding of $\mathrm{C}_{70}$, whereas bulky ones favor the binding of $\mathrm{C}_{60}$.

The change in Gibbs free energy for the reaction 1, $\Delta\left(\Delta G^{\mathrm{o}}\right)_{70-60}=-R T \ln \left(K_{70} / K_{60}\right)$, is calculated from $K_{70} / K_{60} \cdot R$ is the gas constant and $T$ is the temperature $(298 \mathrm{~K})$. Values of $\Delta\left(\Delta G^{\circ}\right)_{70-60}$ are listed in Table 1 along with the change in binding energy at $0 \mathrm{~K}, \Delta\left(\Delta E^{\mathrm{o}}\right)_{70-60}=\Delta E^{\mathrm{o}}{ }_{70}-\Delta E_{60}^{\mathrm{o}}$, obtained from density functional theory (DFT) calculations. ${ }^{13}$ DFT predicted the two different modes of $\mathrm{C}_{70}$ binding to porphyrins, "side-on" and $\mathrm{C}_{60}$-like "end-on" binding. The equatorial belt of $\mathrm{C}_{70}$ is used for the side-on binding, whereas the pole of $\mathrm{C}_{70}$ is used for the end-on binding. The side-on binding offers more contact area to porphyrin than the $\mathrm{C}_{60}$-like end-on binding. Porphyrins 1-3 showing negative values of $\Delta\left(\Delta G^{\circ}\right)_{70-60}$ have $\Delta\left(\Delta E^{0}\right)_{70-60}$ values of -2.6 to $-2.1 \mathrm{kcal} \mathrm{mol}^{-1}$ for the side-on binding and of -0.8 to $-0.4 \mathrm{kcal} \mathrm{mol}^{-1}$ for the end-on binding. On the other hand, porphyrins $\mathbf{4}$ and $\mathbf{5}$ presenting positive values of $\Delta\left(\Delta G^{\circ}\right)_{70-60}$ have $\Delta\left(\Delta E^{\mathrm{o}}\right)_{70-60}$ values of -0.9 to $2.2 \mathrm{kcal} \mathrm{mol}^{-1}$ for the side-on binding and of -0.3 to $-0.5 \mathrm{kcal} \mathrm{mol}^{-1}$ for the end-on binding. The binding energy also suggests a preference for the side-on binding of $\mathrm{C}_{70}$ to non-bulky porphyrins, but no preference toward either side-on or end-on binding of $\mathrm{C}_{70}$ to bulky porphyrins.

Meanwhile, the entropy change involved in the competitive binding of $\mathrm{C}_{60}$ and $\mathrm{C}_{70}$ to porphyrin can be estimated by considering molecular symmetry. ${ }^{17}$ The symmetry number $(\sigma)$ is 60 for spherical $\mathrm{C}_{60}\left(I_{h}\right),{ }^{18} 10$ for ovoid $\mathrm{C}_{70}\left(D_{5 h}\right),{ }^{18}$ and 4 for square planar porphyrin. Porphyrin-fullerene complexes have the symmetry number of 4 for the $\mathrm{C}_{60}$ binding or the end-on binding of $\mathrm{C}_{70}$, and 2 for the side-on binding of $\mathrm{C}_{70}$. The change in symmetry number results in the entropy change by $-R \ln (3)$ for the side-on and by $-R \ln (6)$ for the end-on binding of $\mathrm{C}_{70}$ relative to the $\mathrm{C}_{60}$ binding, respectively.

Thus, the contribution of entropy, $-T \Delta(\Delta S)_{70-60}$, to the change in Gibbs free energy is 0.65 and $1.06 \mathrm{kcal} \mathrm{mol}^{-1}$ for the side-on and end-on binding of $\mathrm{C}_{70}$, respectively. The entropy factor based on molecular symmetry favors the side-on

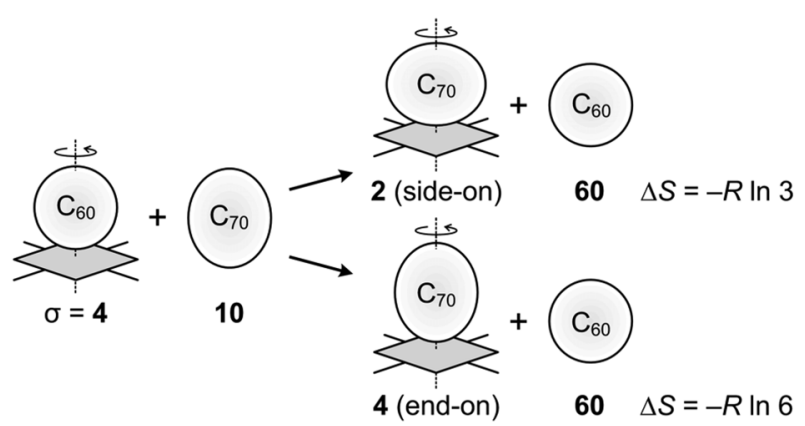

Mass Spectrom. Lett. 2011 Vol. 2, No. 2, 49-52 
binding over the end-on binding and the $\mathrm{C}_{60}$ binding over the $\mathrm{C}_{70}$ binding.

\section{Conclusion}

Meso-substituents in porphyrin affect porphyrin-fullerene interactions. Porphyrins with non-bulky substituents thermodynamically favor the binding of $\mathrm{C}_{70}$ that offers more contact area than the binding of $\mathrm{C}_{60}$, whereas those with bulky substituents show thermodynamic preference for the $\mathrm{C}_{60}$ binding that exerts less steric hindrance to meso-subsituents. The molecular symmetry yields the negative entropy change for the binding of $\mathrm{C}_{70}$ over $\mathrm{C}_{60}$, but less negative entropy change for the side-on binding of $\mathrm{C}_{70}$ than the end-on binding.

\section{Acknowledgments}

We acknowledge the support from the National Research Foundation of Korea (Grant 2010-0027800).

\section{References}

1. Boyd, P. D. W.; Reed, C. A. Acc. Chem. Res. 2005, 38, 235.

2. Bottari, G; de la Torre, G.; Guldi, D. M. Chem. Rev. 2010, $110,6768$.

3. Xiao, J.; Savina, M. R.; Martin, G. B.; Francis, A. H.; Meyerhoff, M. E. J. Am. Chem. Soc. 1994, 116, 9341.

4. Shoji, Y.; Tashiro, K.; Aida, T. J. Am. Chem. Soc. 2004, 126,6570 .

5. Hasobe, T.; Imahori, H.; Kamat, P. V.; Ahn, T. K.; Kim, S.
K.; Kim, D.; Fujimoto, A.; Hirakawa, T.; Fukuzumi, S. J. Am. Chem. Soc. 2005, 127, 1216.

6. Hosseini, A.; Taylor, S.; Accorsi, G; Armaroli, N.; Reed, C. A.; Boyd, P. D. W. J. Am. Chem. Soc. 2006, 128, 15903.

7. Zheng, J.-Y.; Tashiro, K.; Hirabayashi, Y.; Kinbara, K.; Saigo, K.; Aida, T.; Sakamoto, S.; Yamaguchi, K. Angew. Chem. Int. Ed. 2001, 40, 1858.

8. Dudič, M.; Lhoták, P.; Stibor, I.; Petř́ičková, H.; Lang, K. New J. Chem. 2004, 28, 85.

9. Marois, J.-S.; Cantin, K.; Desmarais, A.; Morin, J.-F. Org. Lett. 2008, 10, 33.

10. Boyd, P. D. W.; Hodgson, M. C.; Rickard, C. E. F.; Oliver, A. G; Chaker, L.; Brothers, P. J.; Bolskar, R. D.; Tham, F. S.; Reed, C. A. J. Am. Chem. Soc. 1999, 121, 10487.

11. Bhattacharya, S.; Shimawaki, T.; Peng, X.; Ashokkumar, A.; Aonuma, S.; Kimura, T.; Komatsu, N. Chem. Phys. Lett. 2006, 430, 435 .

12. Hong, E. S.; Yoon, H.-J.; Kim, B.; Yim, Y.-H.; So, H.-Y.; Shin, S. K. J. Am. Soc. Mass Spectrom. 2010, 21, 1245.

13. Jung, S.; Seo, J.; Shin, S. K. J. Phys. Chem. A 2010, 114, 11376.

14. Cristadoro, A.; Räder, H. J.; Müllen, K. Rapid Commun. Mass Spectrom. 2008, 22, 2463.

15. Lichtenberger, D. L.; Nebesny, K. W.; Ray, C. D.; Huffman, D. R.; Lamb, L. D. Chem. Phys. Lett. 1991, 176, 203.

16. Lichtenberger, D. L.; Rempe, M. E.; Gogosha, S. B. Chem. Phys. Lett. 1992, 198, 454.

17. McQuarrie, D. A. Statistical Mechanics, University Science Books: Sausalito, 2000.

18. Slanina, Z.; Uhlík, F.; Boltalina, O. V. Phys. Solid State 2002, 44, 548. 